\title{
Pesticide Knowledge, Attitudes, and Clothing Practices of Turkish Farmers
}

\author{
Mercan Derafshi (Corresponding Author) \\ Department of Design Housing and Merchandising \\ Oklahoma State University, Stillwater, 74078-USA
}

Tel: 1-509-592.8841Ｅ-mail: mercan@okstate.edu

\begin{abstract}
Catherine Black
School of Human Sciences, Mississippi State University, Mississippi State, 39762-USA

Tel: 1-662-325.6555_E-mail: cmb1356@msstate.edu
\end{abstract}

\author{
Robert Agnew \\ Dept. of Fire Protection and Safety Engineering Technology \\ Oklahoma State University, Stillwater, 74078-USA
}

Received: November 8, 2016 Accepted: December 8, 2016

doi:10.5296/emsd.v6i1.10271 URL: https://doi.org/10.5296/emsd.v6i1.10271

\begin{abstract}
The purpose of this study was to assess Turkish farmers' knowledge, attitudes, and clothing practices during pesticide activities. Seventy male farmers from seven districts of the Aegean region of Turkey were interviewed. Farmers indicated a high level of knowledge of adverse health effects associated with pesticides. In contrast to their level of knowledge, over $50 \%$ of the farmers had the attitude that pesticides would not be harmful to them. The type of clothing most often worn further supported the farmers' attitudes: T-shirts or long-sleeve shirts, denim pants, leather shoes, or sandals, all of which provide little protection. Therefore, farmers' knowledge on the harmful effects of pesticides did not correlate with their clothing practices. Additionally, farmers' attitudes and clothing practices were inconsistent with each other. A weak but significant correlation between attitudes and clothing practices with a negative direction also supported this. Furthermore, participant farmers indicated bringing contaminated clothing inside the home and laundering contaminated work clothes with
\end{abstract}


regular family clothes, potentially exposing family members by take-home contamination. These findings suggest that the development of training programs to reduce pesticide exposure would benefit Turkish farmers.

Keywords: Aegean farmers, Personal protective clothing, Pesticide activities

\section{Introduction}

Turkey has more than 8 million farmers (The Union of Chambers and Commodity Exchanges of Turkey, 2013). Of those, 2.3 million farmers are registered with the Turkish Ministry of Agriculture, Food, and Animal Affairs, thereby indicating that the majority of the farmers may not receive crop protection support (Ministery of Food Agriculture and Livestock General Directorate of Vegetative Production, 2016). Farmers in the Aegean region of Turkey practice intensive agriculture that involves growing various fruits and vegetables at farms. Because of this crop variety, pesticide application in the Aegean region is heterogeneous and accounts for over one-third of the pesticide usage in Turkey. Izmir province in the Aegean region, alone, accounts for approximately $20-25 \%$ of the pesticide usage in Turkey (Delen et al., 2005).

Pesticides are considered a fundamental component of today's farming and play a vital role in maintaining high agricultural productivity. However, a growing body of research provides evidence that pesticide poisoning is a major health problem (Jones, Mabota, \& Larson, 2009; Ohayo-Mitoko, Heederik, Kromhout, Omondi, \& Boleij, 1997; Salvatore et al., 2008; A. Singh \& Kaur, 2012; Zyoud et al., 2010). Unintentional exposure remains a health hazard for many farmers, particularly in developing countries. For instance, improper methods of pesticide application in the Philippines, unsafe work practices and inadequate protective equipment in India, false beliefs of Turkish fruit growers (i.e. more pesticides increase crop yield and the quality), and the use of organophosphates as insecticides in Turkey, contribute to the increasing rates of pesticide poisoning among farmers, in addition to posing a threat to the environment (Bakirci, Acay, Bakirci, \& Otles, 2014; Isin \& Yildirim, 2007; Lu, 2009; A. Singh \& Kaur, 2012; Zeren, Dikmen, \& Taga, 2002).

Farmers' knowledge of potential health risks associated with pesticide handling is important in the prevention of exposure to pesticides. Unavailability of information and inadequate understanding of toxicity are two main factors contributing to farmers' low level of knowledge regarding health risks associated with pesticide handling (Devi, 2009; Jones et al., 2009; Ngowi, Maeda, \& Partanen, 2001; Nicol \& Kennedy, 2008). A study of pregnant Thai women found that participants had a relatively high level of knowledge about pesticides, with most particpants answering over $80 \%$ of the questions correctly. The authors identified two areas of knowledge with lower median scores; pesticide toxicity symptoms and pesticide exposure intake routes (Lorenz et al., 2012). Similarly, Weng and Black (2015) reported a high level of knowledge and one or more toxicity symptoms in Taiwanese farm workers. In another study, farmers from the Gaza Strip in Palestine, reported high level of education and frequent poisoning (Yassin, Mourad, \& Safi, 2002). Cotton growers in Mozambique that received health information were a member of producer network, or received training on protective equipment reported a higher level of knowledge compared to the farmers who did 
not receive any trainings (Jones et al., 2009).

Realistic attitudes and beliefs about pesticides can greatly increase farmers' capacity to protect themselves against pesticide hazards. Therefore, investigating farmers attitude regarding pesticide application is imperative (Stone, Padgitt, Wintersteen, Shelly, \& Chisholm, 1994). Attitudes that farmers are not susceptible to the health effects of pesticides were common among pregnant women of Thailand (Lorenz et al., 2012). Also, farmers in the Gaza strip believed that they could develop resistance to pesticides (Yassin et al., 2002). Such attitudes places farmers and other sub-populations at a risk from pesticide exposure and may discourage farmers from taking protective measures (Lorenz et al., 2012). In addition, personal protective equipment (PPE) and personal protective clothing (PPC) might not benefit farmers during the application process if farmers are not using them correctly (DeJonge, Vredevoogd, \& Henry, 1983; Rucker, McGee, \& Chordas, 1986; Stone et al., 1994).

European Crop Protection Association is reaching out to small-scale farmers and promoting safe and sustainable use of pesticides. Turkey's Ministry of Food Agriculture and Livestock has collaborated with the European Crop Protection Association in developing guidelines, manuals, videos, and trainings for pesticide applicators (http://www.ppe-info.eu/tr). Using PPE is one method to decrease pesticide exposure (Damalas, Georgiou, \& Theodorou, 2006; Salvatore et al., 2008). Unfortunately, research in this area concludes that farmers work with minimal protection. For example, in a recent study, the majority of the farmers in India indicated working barefoot, without goggles or gloves, and only covered their faces with a cloth during pesticide activities (Singh \& Gupta, 2009). Similarly, a significant number of Greek farmers (46\%) did not use any protective equipment when spraying pesticides (Damalas et al., 2006). Further unsafe behaviors were also reported including storing agricultural pesticides, contaminated clothing, and shoes inside the home (Curwin, Sanderson, Reynolds, Hein, \& Alavanja, 2002), storing pesticides in close proximity to food and household items (Kachaiyaphum, Howteerakul, Sujirarat, Siri, \& Suwannapong, 2010), washing PPC along with family clothes in the same washing machine (Salvatore et al., 2008), and unsafe disposing of pesticide containers (Ibitayo, 2006). As noted above, these unsafe practices might stem from farmers' lack of knowledge and/or understanding of safe application of pesticides. Therefore, measuring farmers' existing knowledge about the use of pesticides helps pave the way for future respective educational programs.

The purpose of this study was, therefore, to assess Turkish farmers' knowledge, attitudes, and clothing practices regarding pesticide activities. We suggest that obtaining relevant information is essential to understanding the factors that influence Turkish farmers' willingness to use PPE and PPC and to develop intervention programs that focus on the prevention of pesticide exposures. The following research questions were developed:

1) What are Turkish farmers' general and specific knowledge associated with pesticides?

2) What are Turkish farmers' attitudes toward pesticides?

3) What are Turkish farmers' clothing practices? 
4) Is there a correlation among Turkish farmers' knowledge, attitudes, and clothing practices?

\section{Methods}

\subsection{Study Participants}

Seventy male farmers from seven districts (Kemalpasa, Bornova, Urla, Torbali, Foca, Menemen, and Menderes) of the Aegean region of Turkey were interviewed in August 2012. The districts were randomly selected from the Ministry of Agriculture Provincial Directorate of Izmir's website (Republic of Turkey Ministiry of Food Agriculture and Livestock, 2012). After consulting with each district's directorate, it was determined that the interviews would be conducted at some coffee houses in the Aegean region. Turkish farmers, of all demographics, commonly spend daily time with colleagues, friends, and neighbors at traditional coffee houses called Kahve. As farmers sat down in the Kahve, they were informed about the study and asked about their willingness to participate. Those farmers with pesticide application experience were eligible to participate in the study. One of the authors interviewed one farmer per table. Selecting participants in this manner allowed the responses to be discrete from other potential participants. The interview process continued until informational redundancy and data saturation were achieved. Only five farmers did not agree to participate in the study. Institutional Review Board approval was received prior to the study.

\subsection{Interview Questions}

A semi-structured interview schedule was pilot-tested with 10 colleagues from Ege University, Turkey; revisions were made per their suggestions. Demographic questions included gender, age, education level, marital status, experience in farming, farm size, types of crops grown, types of pesticide used, and farmers' monthly income. Farmers' knowledge was measured using 19 questions adapted from Jones et al. (2009). Knowledge information included both general and specific knowledge of health risk and knowledge of protective equipment. Farmers who responded 'Yes' to the general knowledge question and 8 of the 12 specific health questions were rated as having high knowledge, the remaining respondents were rated as having low knowledge of health risks. Similarly, farmers who responded 'Yes' to the general knowledge question and "Yes" to 4 of the 5 specific protective equipment questions were rated as knowledgeable of protective equipment (Table 3 and Table 4). An overall knowledge index was calculated for each participant with scores ranging from 0 to 19 . Stone et al. (1994) attitude statements were used to assess the participating Turkish farmers' attitudes toward pesticide application. Attitude statements were presented using a 5-point Likert scale. An overall attitude score was calculated for each participant. Farmers' clothing practices were addressed by questions adapted from (Perkins, Crown, Rigakis, \& Eggertson, 1992). Clothing practices included questions about farmers' actual behaviors, including their work clothes worn while mixing pesticides, applying pesticides, and cleaning contaminated equipment, comfort and restriction regarding work clothes, location of donning and doffing, methods of laundering, and storage of contaminated work clothes.

Based on the guidelines by the European Crop Protection Association 


\section{Macrothink}

(http://www.ppe-info.eu/tr\#) the participants received an overall score for the level of protection of their clothing, with a maximum possible score of 10. Participants who wore high protection clothing (apron, coverall, goggles, respirator, and/or mask) were given a score of 10. Participants who indicated that they wore moderate protection (rubber gloves, rubber boots, wide brimmed hats, and/or headscarf), adapted from European Crop Protection Association, were given 5 points. Items with low protection value that were not listed as protective clothing, such as caps, leather shoes, denim pants, long pants, long sleeved shirt, T-shirt, and sandals, scored 1 point.

\subsection{Statistical Analysis}

Frequencies and percentages were used to summarize and describe the data. Correlations among overall knowledge, attitudes, and clothing practices scores were calculated using non-parametric Spearman's rho and parametric Pearson Product Moment Correlation. Because of the non-parametric and rank-order nature of clothing practices with three levels (high, moderate, low protection), the Spearman's rho was carried out to test the relationship between clothing practices and knowledge and clothing practices and attitudes. Pearson Product Moment Correlation was used to test the relationship between two continuous variables, knowledge and attitudes. For the open-ended questions, each response was analyzed for specific keywords (e.g. risk, usage, clothing) relevant to knowledge, attitudes, and clothing practices. The analyzed responses were related to human and environment health, pesticide application, clothing comfort, and cultural norms. The responses were then gathered under the one category of 'farmers' statements'.

\section{Results}

\subsection{Demographic Characteristics of the Sample}

The seventy male farmers were predominately aged 50 and over $(68 \%)$, married (90\%) with two or three children (70\%) (Table 1). The majority $(60 \%)$ had primary education. Of the respondents who reported their income level, 41\% indicated an income less than 5,000 Turkish Lira/month (\$2800 U.S.). Primary education is common for men of this age group, and the income reflects an income above average for residents of Turkey (http://www.tradingeconomics.com/turkey/wages). 
Table 1. Demographics of farmers in seven districts in the Aegean region of Turkey

\begin{tabular}{|l|l|l|}
\hline & N & $\%^{*}$ \\
\hline Age & & \\
\hline$<30$ & 5 & 7 \\
\hline $30-39$ & 11 & 16 \\
\hline $40-49$ & 6 & 9 \\
\hline $50-59$ & 22 & 31 \\
\hline $60-69$ & 17 & 24 \\
\hline$\geq 70$ & 9 & 13 \\
\hline Marital status & & \\
\hline Married & 63 & 90 \\
\hline Single & 7 & 10 \\
\hline Number of children & & \\
\hline None & 09 & 13 \\
\hline 1 & 7 & 10 \\
\hline 2 & 29 & 41 \\
\hline 3 & 20 & 29 \\
\hline 4 & 2 & 3 \\
\hline 5 & 2 & 3 \\
\hline 6 & 1 & 1 \\
\hline Education & & \\
\hline No School & 1 & 1 \\
\hline Primary School & 42 & 60 \\
\hline Secondary School & 9 & 13 \\
\hline High School & 15 & 21 \\
\hline University & 3 & 4 \\
\hline Income/month** & & \\
\hline $1000-5000$ & 29 & 41 \\
\hline $7000-10000$ & 7 & 10 \\
\hline Not responded & 34 & 49 \\
\hline & & \\
\hline & & \\
\hline & & \\
\hline
\end{tabular}

* Note may not sum to $100 \%$ due to rounding

$* * 1000$ Turkish Lira $(\mathrm{TL})=\$ 560$ USD

Over half the farmers (58\%) had 40 or more years of farming experience (Table 2). Seventy-three percent of the farmers owned farms of 8 hectares or less, indicating that the participants were small-scale landowners. Farmers reported growing a variety of fruits including cherries, grapes, peaches, oranges, and lemons. Tractor-mounted sprayers, either lance sprayers $(41 \%)$ or boom sprayers $(21 \%)$, or backpack sprayers $(31 \%)$ were used by most of the farmers. The most common pesticides used were insecticides (96\%), herbicides $(85 \%)$, or fungicides $(82 \%)$. More than half of the farmers $(58 \%)$ had received training when 
they purchased pesticides. Farmers were not able to answer specific questions regarding active ingredients of pesticides they used (Table 3).

Table 2. Crop information of 70 male farm workers in the Aegean region of Turkey

\begin{tabular}{|l|l|l|}
\hline & N & $\%^{*}$ \\
\hline Region & & \\
\hline Kemalpasa & 21 & 30 \\
\hline Bornova & 18 & 26 \\
\hline Urla & 10 & 14 \\
\hline Torbali & 7 & 10 \\
\hline Foca & 6 & 9 \\
\hline Menemen & 6 & 9 \\
\hline Menderes & 2 & 3 \\
\hline Farming experience (years) & & \\
\hline$<10$ & 5 & 7 \\
\hline $10-27$ & 16 & 23 \\
\hline $30-38$ & 8 & 11 \\
\hline $40-48$ & 17 & 24 \\
\hline $50-56$ & 17 & 24 \\
\hline$\geq 60$ & 7 & 10 \\
\hline Farm size (Hectares) & & \\
\hline$\leq 8 * *$ & 51 & 73 \\
\hline $10-40$ & 17 & 24 \\
\hline$\geq 100$ & 2 & 3 \\
\hline Crops & & \\
\hline Cherries & 22 & 31 \\
\hline Corn & 6 & 9 \\
\hline Cotton & 11 & 16 \\
\hline Grapes & 14 & 20 \\
\hline Olives & 7 & 10 \\
\hline Orange \& Lemon & 1 & 1 \\
\hline Peaches & 2 & 3 \\
\hline Vegetables & 7 & 10 \\
\hline & & \\
\hline
\end{tabular}

* Note may not sum to $100 \%$ due to rounding

$* * 8$ hectares $=19.7$ acres $(1$ hectare $=2.47$ acres $)$ 
Table 3. Farm activates

\begin{tabular}{|l|l|l|}
\hline & $\mathrm{N}$ & $\%^{*}$ \\
\hline Application methods (Sprayer type) & & \\
\hline Tractor mounted & & \\
\hline 400L. Lance & 29 & 41 \\
\hline 400L. Boom & 15 & 21 \\
\hline Backpack sprayer & & \\
\hline 12L. Lance & 22 & 31 \\
\hline Tractor mounted or backpack & & \\
\hline 12L. \& 400L. Lance & 4 & 6 \\
\hline Types of Pesticides Used & & \\
\hline Insecticides & 68 & 96 \\
\hline Herbicides & 60 & 85 \\
\hline Fungicides & 58 & 82 \\
\hline Copper Sulfate & 35 & 49 \\
\hline Rodenticides & 16 & 23 \\
\hline Acaricides & 13 & 18 \\
\hline Mollusicides & 13 & 18 \\
\hline Nematocides & 8 & 11 \\
\hline Fumigants & 3 & 4 \\
\hline
\end{tabular}

* Note may not sum to $100 \%$ due to rounding

\subsection{Turkish Farmers' Knowledge of Health Risks, PPE and PPC}

Seventy percent of the farmers indicated having general knowledge of health risks associated with pesticides. Out of this group of farmers, $67 \%$ scored high on both general and specific knowledge questions and fit into the high knowledge category (Table 4).

Ninety-four percent of the farmers believed that health risks could be severe. Farmers were also aware of the most common routes of exposure for pesticides and had knowledge of the symptoms caused by pesticides, including headaches (96\%), eye irritation (97\%), and nausea and vomiting (99\%). Ninety-nine percent of the farmers believed taking protective measures are important including wearing PPC (Table 5). All the farmers scored high for specific knowledge questions regarding personal protective clothing. Therefore, based on these findings, Turkish farmers reported high level of knowledge of health risks and protective clothing. 
Table 4. Knowledge of health risks

\begin{tabular}{|l|l|l|l|l|}
\hline & \multicolumn{2}{l|}{ No } & \multicolumn{2}{l|}{ Yes } \\
\hline & N & $\%$ & N & $\%$ \\
\hline General Knowledge & & & & \\
\hline $\begin{array}{l}\text { 1) Do you have a general knowledge of health risks } \\
\text { associated with pesticide use? }\end{array}$ & 21 & 30 & 49 & 70 \\
\hline Specific Knowledge & & & & \\
\hline $\begin{array}{l}\text { 1) Do you believe that health risk due to handling of } \\
\text { pesticide is severe for you and our family members? }\end{array}$ & 4 & 6 & 66 & 94 \\
\hline $\begin{array}{l}\text { 2) Do you know if pesticides can enter your body } \\
\text { through the following ways? }\end{array}$ & & & & \\
\hline 2a) Skin & 1 & 1 & 69 & 99 \\
\hline 2b) Mouth & 0 & 0 & 70 & 100 \\
\hline 2c) Nose & 1 & 1 & 69 & 99 \\
\hline $\begin{array}{l}\text { 3) Are you aware that the following symptoms are } \\
\text { caused by pesticide exposure? }\end{array}$ & & & \\
\hline 3a) Headaches & 3 & 4 & 67 & 96 \\
\hline 3b) Eye irritation & 2 & 3 & 68 & 97 \\
\hline 3c) Nauseas and Vomiting & 1 & 1 & 69 & 99 \\
\hline 3d) Dizziness and Muscle weakness & 4 & 6 & 66 & 94 \\
\hline 3e) Difficulty in breathing & 5 & 7 & 65 & 93 \\
\hline 3f) Diarrhea & 5 & 7 & 65 & 93 \\
\hline 3g) Chest Pain & 6 & 8 & 64 & 91 \\
\hline 3h) Skin irritation & 2 & 3 & 68 & 97 \\
\hline
\end{tabular}

Table 5. Knowledge of PPE and PPC

\begin{tabular}{|l|l|l|l|l|}
\hline & \multicolumn{2}{l|}{ No } & \multicolumn{2}{l|}{ Yes } \\
\hline & $\mathrm{N}$ & $\%$ & $\mathrm{~N}$ & $\%$ \\
\hline General Knowledge & & & & \\
\hline 1) Do you believe that protective measures are important? & 1 & 1 & 69 & 99 \\
\hline Specific Knowledge & & & & \\
\hline $\begin{array}{l}\text { 2) From the following list of protective clothing against pesticide } \\
\text { exposure which do you believe to be effective? }\end{array}$ & & & \\
\hline 2a) Gloves & 0 & 0 & 70 & 100 \\
\hline 2b) Rubber boots & 3 & 4 & 67 & 96 \\
\hline 2c) Masks & 0 & 0 & 70 & 100 \\
\hline 2d) Protective glasses & 0 & 0 & 70 & 100 \\
\hline 2e) Long trousers and long sleeved shirt & 0 & 0 & 70 & 100 \\
\hline
\end{tabular}




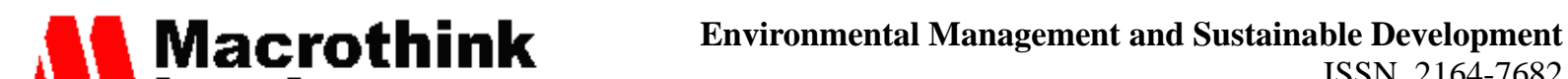 Institute ${ }^{\mathrm{TM}}$

\subsection{Turkish Farmers' Attitudes}

Turkish farmers' attitudes toward pesticide application yielded confounding results (Table 6). Even though the participating farmers exhibited a high level of knowledge of specific health risks associated with pesticides, 50\% of the participants agreed that most farmers are physically strong enough to handle the exposure to pesticides without being harmed. In contrast, $96 \%$ believed that their job, as pesticide handlers, was associated with health risks, including cancer, but that would not be the case for them.

The majority of farmers $(73 \%)$ believed that the farmers they knew followed label instructions very closely, while the remaining informants believed that some farmers did not have sufficient knowledge and/or training to apply pesticides. Fifty-nine percent were also aware that pesticides can be absorbed through their clothing when they applied pesticides; nevertheless, $67 \%$ believed that the clothing they wear was effective in reducing pesticide exposure.

Turkish farmers also expressed concerns for the environment. For example, $97 \%$ of the farmers believed that pesticides disrupt the balance between nature (soil, plants, animals) and humans. Over of half the farmers $(61 \%)$ believed that the government does not have adequate rules and regulations on the use of pesticides. Most (79\%) also believed that the government permits the marketing of pesticides before knowing about the hazards. 
Table 6. Turkish farmers' attitudes toward pesticide application

\begin{tabular}{|l|l|l|l|l|l|l|l|}
\hline Attitude Statements & \multicolumn{2}{|l|}{$\begin{array}{l}\text { Strongly } \\
\text { Agree/Agree }\end{array}$} & \multicolumn{2}{l|}{ Neutral } & \multicolumn{2}{l|}{$\begin{array}{l}\text { Strongly } \\
\text { Disagree/Disagree }\end{array}$} \\
\hline $\begin{array}{l}\text { Continued use of pesticides will likely } \\
\text { produce cancer and leukemia in humans }\end{array}$ & 62 & 89 & 2 & 3 & 6 & $8 *$ \\
\hline $\begin{array}{l}\text { Most farmers are tough enough to take } \\
\text { exposure to pesticides without harm** }\end{array}$ & 35 & 50 & 1 & 1 & 34 & 49 \\
\hline $\begin{array}{l}\text { There is too much concern over the } \\
\text { harmful effects of pesticides and too } \\
\text { little about their benefits }\end{array}$ & 61 & 87 & 1 & 1 & 8 & 11 \\
\hline $\begin{array}{l}\text { The use of pesticides upsets the balance } \\
\text { of nature between soil, plants, animals, } \\
\text { and people }\end{array}$ & 68 & 97 & 0 & 0 & 2 & 3 \\
\hline $\begin{array}{l}\text { Risks are just part of the job in pesticide } \\
\text { application }\end{array}$ & 67 & 96 & 1 & 1 & 2 & 3 \\
\hline $\begin{array}{l}\text { A careful farmer can minimize dangers } \\
\text { associated with pesticides }\end{array}$ & 68 & 97 & 0 & 0 & 2 & 3 \\
\hline $\begin{array}{l}\text { Farmers can avoid pesticides on their } \\
\text { skin if they are careful }\end{array}$ & 65 & 93 & 0 & 0 & 5 & 7 \\
\hline $\begin{array}{l}\text { Most farmers I know follow label } \\
\text { instruction very closely }\end{array}$ & 51 & 73 & 0 & 0 & 19 & 27 \\
\hline $\begin{array}{l}\text { The amount of pesticides that gets on } \\
\text { clothing is nothing compared to the } \\
\text { amount of pollution in the air** }\end{array}$ & 26 & 37 & 2 & 3 & 42 & 59 \\
\hline $\begin{array}{l}\text { The work clothing, I wear is effective in } \\
\text { reducing my exposure to pesticides }\end{array}$ & 47 & 67 & 2 & 3 & 21 & 30 \\
\hline $\begin{array}{l}\text { We already have too much regulation on } \\
\text { the use of pesticides** }\end{array}$ & 24 & 34 & 3 & 4 & 43 & 61 \\
\hline $\begin{array}{l}\text { The government permits pesticides to be } \\
\text { marketed before adequate information } \\
\text { regarding the potential hazards is known }\end{array}$ & 55 & 79 & 1 & 1 & 14 & 20 \\
\hline
\end{tabular}

* Note may not sum to $100 \%$ due to rounding

** Note Reverse coded ( $5=$ strongly agree, $1=$ strongly disagree $)$

\subsection{Turkish Farmers' Clothing Practices}

Most of the farmers reported wearing denim pants (91\%) and long-sleeved shirts (84\%) for comfort. In terms of personal protective equipment, less than half of the farmers reported using masks $(37 \%)$ or goggles $(34 \%)$. For protection purposes, some farmers $(24 \%)$ wore a traditional Posu scarf when working at the fields. The purpose of wearing a scarf was to 


\section{Macrothink}

shield their faces from pesticides and protect their head from the sun. The typical clothing worn and equipment used by the farmers are presented in Figure 1. Sixty-seven percent of the respondents indicated that they would be willing to purchase protective clothing that was comfortable and would protect them from pesticide exposure. Participants, in addition, reported that they wore the same clothes in all stages of pesticide handling. Furthermore, the farmers mixed pesticides in the field, where they were later applied.

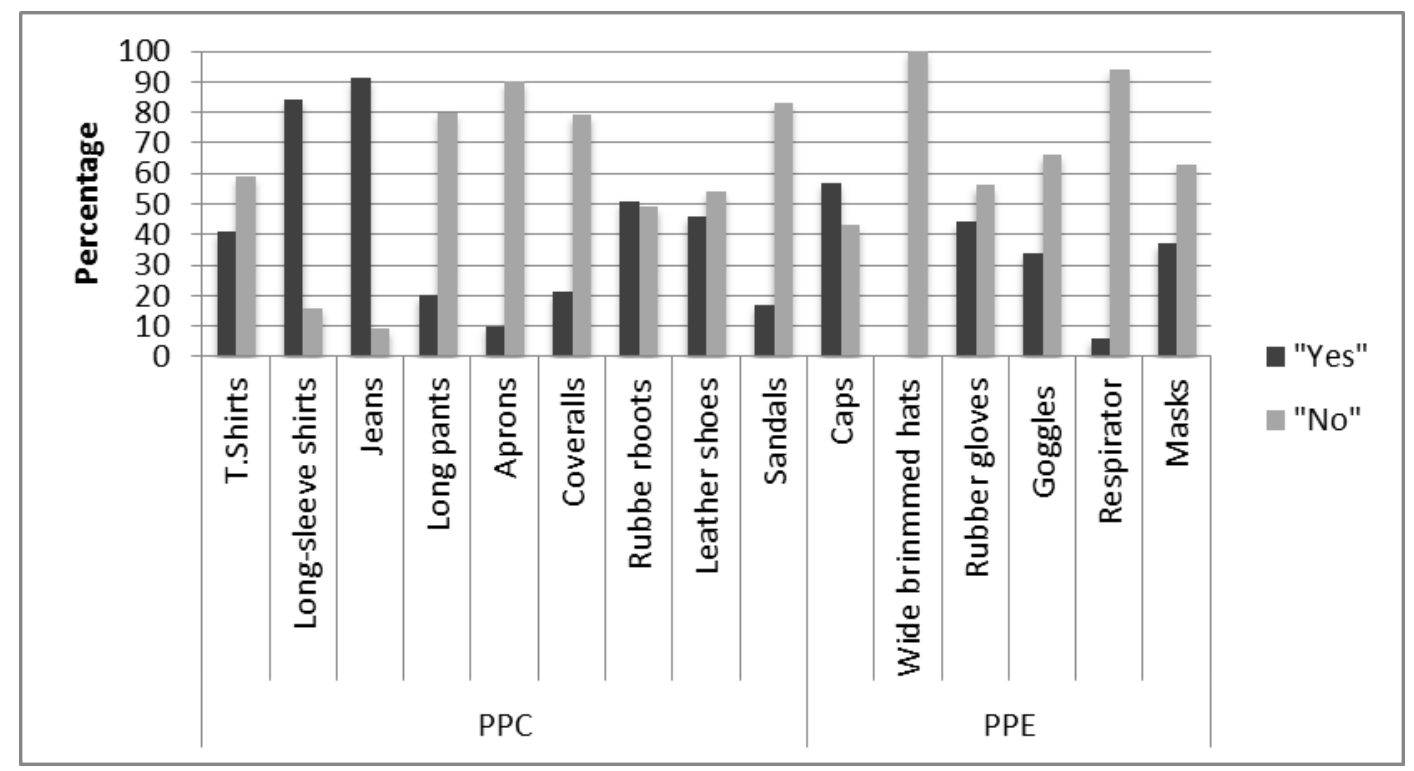

Figure 1. PPE and PPC used by Turkish Farmers

\subsection{Location of Donning/Doffing, Storage, and Laundering}

While the majority of farmers donned and doffed their work clothes outside the home, a large number donned (37\%) and doffed (30\%) their clothes inside their homes (Figure 2). Some farmers indicated that they stored their contaminated work clothes inside their homes $(25 \%)$, and only $17 \%$ reported storing their clothes in a separate container. Half of the farmers did not take a shower within 15 minutes after applying pesticides. The main reason for this was that farmers did not have washing or decontamination facilities at their farms, and their houses were not within a close proximity of the farms. In addition, most of the farmers washed their work clothes in a bucket (59\%); others washed their clothes in a washing machine, separately from their family clothes, while four farmers indicated that they washed their work clothes with their family's clothes. 


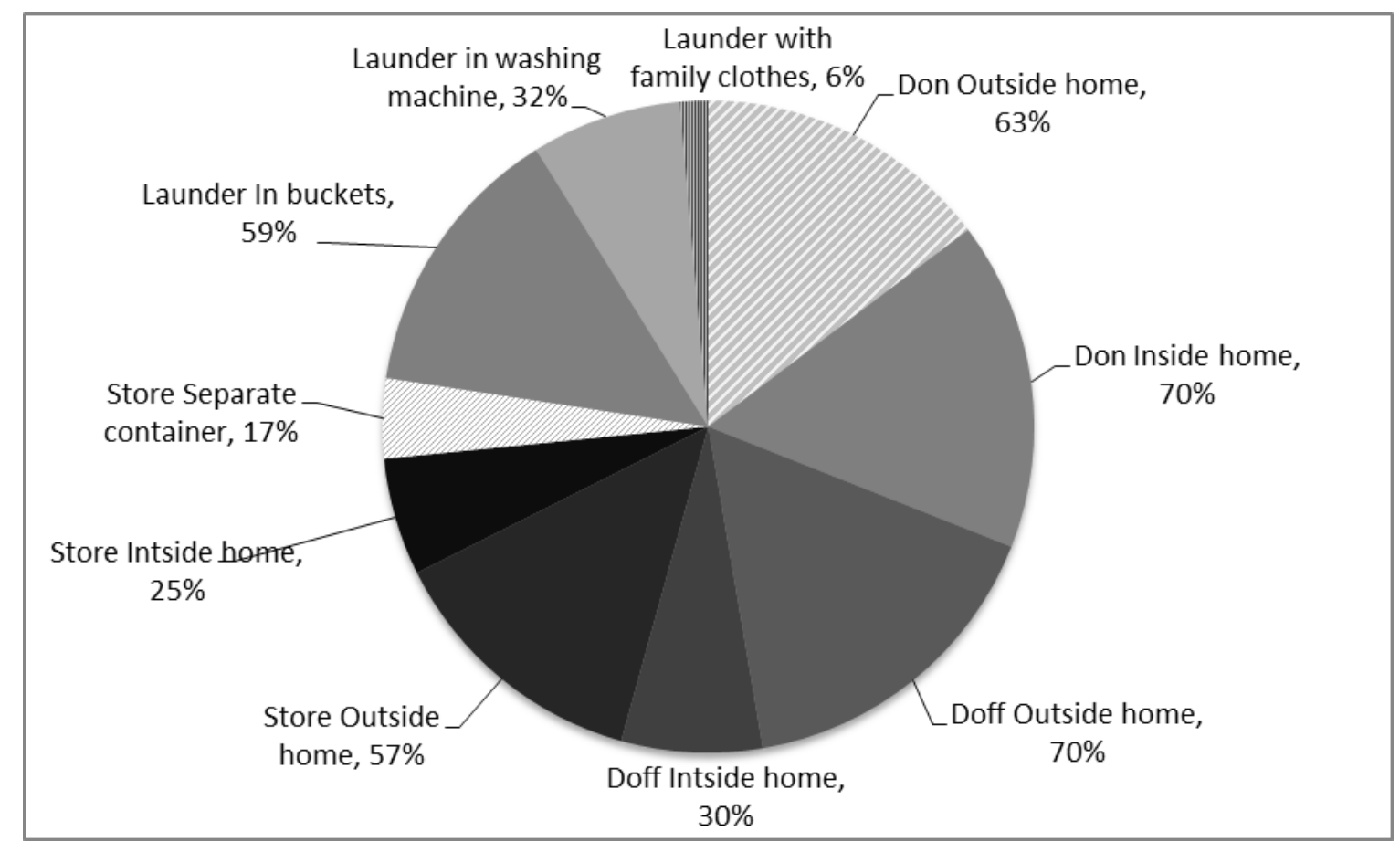

Figure 2. Pesticide activities include donning, doffing, storage, and laundering work clothes

\subsection{Farmers 'Statements}

Open-ended statements helped illuminate the farmers' structured responses. Risky behavior was reported despite the farmers' high level of knowledge. For example, one participant stated, "I smoke 40 cigarettes a day; if they don't poison me, then pesticides won't either." The same participant scored high on knowledge and indicated that pesticides could cause cancer. However, he thought that this was not the case for him. Other risky behaviors observed by the researcher were smoking during pesticide handling, mixing pesticides, and cleaning contaminated equipment in a gas station. Some concerns over incorrect pesticide handling were also stated;

"I have been trained to apply pesticides to orchards as well as my olive trees. I am a certified pesticide applicator. I know there are farmers that don't know what they are doing when it comes to mixing [pesticides]. They damage trees and the environment by excessive dosages of pesticides. Farmers should be made conscious of how to mix pesticides. It would be helpful because people [farmers] do not know how much they actually need to mix and apply."

Farmers mentioned that they did not receive training on protective clothing for pesticide application, and therefore, assumed that their work clothes provided sufficient protection. It is evident that some farmers sacrificed their safety for comfort, while applying pesticides. One participant, for example, stated that:

"Sometimes when I apply pesticides it gets so hot that I wear a polo shirt. The collar is really nice and keeps me cool. I even wear shorts on hot days." 
The analysis of the data showed that self-esteem and the desire to look "normal" were raised as reasons for not choosing to wear coveralls. One participant reported that:

"I want my work clothes to protect me from pesticides and also look good on me so that I can wear it when I go to coffee house to see my friends. I don't want to have to change my clothes every time I leave the farm..."

The farmers repeatedly mentioned aesthetics of work clothes was of importance to them such that the farmers expressed feeling "unusual" and "embarrassed" when putting on coveralls.

\subsection{Correlations among Knowledge, Attitudes, and Clothing Practices}

Several correlations were identified that provided an overall perspective about the interrelated nature of knowledge, attitudes, and clothing practices, strengthening the confounding message presented in the previous results and findings. There was a negative, significant correlation between attitudes and clothing practices $(r=-0.35, p<0.01)$. The weak association in a negative direction supports the trend that Turkish farmers' attitudes are not necessarily reflected in their clothing practices. There was also a non-significant relationship between farmers' knowledge and attitudes $(r=-0.2, p>0.10)$, as well as knowledge and clothing practices $(r=0.2, p>0.10)$. The lack of significant relationships supports the mixed messages previously reported.

\section{Discussion}

Similar to farmers in Mozambique, Northern Thailand, and Nepal, results of this study suggest that Turkish farmers' knowledge regarding health risks associated with pesticides is high (Grieshop, 1988; Jones et al., 2009; Lorenz et al., 2012). Given the mature age of the participants (68\% over 50 years), high literacy rate, and farming experience; older farmers should be more knowledgeable (Devi, 2009; Jones et al., 2009). Singh and Gupta (2009) reported that farmers suffered from symptoms including nausea and eye itchiness, headache, and chest tightness. Farmers in the current study also indicated experiencing one or more of these symptoms. Former experience of symptoms may also account for their high level of knowledge of health risks associated with pesticides. Furthermore, when compared to Greek farmers (Damalas et al., 2006), Turkish farmers were more aware of pesticide exposure routes.

Intensive agriculture and excessive application of pesticides in the Aegean region will inevitably lead to adverse health effects unless preventive measures are taken (Isin and Yildirim, 2007). However, the desire for higher crop yields and farmers' unwillingness to take protective measures is reflected in their attitudes (beliefs) and clothing practices. Turkish farmers believed that they would not be harmed by pesticides; yet, they also believed that pesticides have adverse health effects and may cause cancer. This is an example of how participants' knowledge is not consistent with their attitudes and farming practices. Additionally, attitudes such as the farmers' perceived insusceptibility to the health effects of pesticides, may discourage them from wearing appropriate protective clothing (Lorenz et al., 2012). This finding is similar to that of Yassin et al. (2002) but in contrast with Stone et al. (1994). One possible explanation for the differences between Turkish and Iowa farmers in 
Stone et al. (1994) study may be due to the training and support American farmers received. Iowa farmers had Pesticide Applicator Training (PAT) and frequently can refer to Iowa State University Extension specialists for guidance. Furthermore, Stone et al. (1994) suggested that Pesticide Applicator Training (PAT) may diminish negative attitudes toward governmental regulations. In contrast, Turkish farmers expressed negative attitudes toward existing governmental rules and regulations with respect to pesticides. Although, Turkish farmers believed there were not sufficient regulations, their attitude of their own insusceptibility toward pesticide exposure may suggest that some farmers were/are overlooking the existing regulations.

Furthermore, the farmers' attitudes and clothing practices were, at times, inconsistent with each other. The Turkish farmers believed that their current work clothing provided effective protection and was efficient in reducing pesticide exposure. For comfort purposes, the majority of the participating Turkish farmers wore denim pants and long-sleeved shirts during pesticide activities. However, the clothing items do not fully protect farmers, especially when long sleeves are rolled up while mixing pesticides. Similar clothing was also worn by Greek and Thai farmers (Damalas et al., 2006; Kachaiyaphum et al., 2010). Denim pants and long-sleeve shirts are not recommended for pesticide application, because of their tendency to absorb and hold pesticide next to the body (Stone et al., 1994).

Some farmers were concerned about the lack of protection from their spraying equipment, especially leakage from backpack sprayers onto their neck, shoulders, back, and waist areas. It was brought to the researchers' attention that Turkish farmers wore the same clothing in all three stages of pesticide activities, and then, left their farms to perform other activities without changing their work clothes. It is appropriate to note that these unsafe pesticide practices are not aligned with the European Crop Protection Commission guidelines. When farmers are directly exposed to pesticides, they may contaminate surfaces upon contact. Therefore, friends and family members may be exposed by take-home contamination (Curwin et al., 2002).

Turkish farmers practiced, storing pesticide containers inside their homes, doffing clothing inside their homes, and washing contaminated work clothes with general family laundry. Unsafe behaviors reported in literature include storing agricultural pesticides, contaminated clothing, and shoes inside the home (Curwin et al., 2002), storing pesticides near to food and household items (Kachaiyaphum et al., 2010), washing PPC along with family clothes in the same washing machine (Salvatore et al., 2008), and unsafe disposing of pesticide containers (Ibitayo, 2006).

\section{Conclusions}

Based on the results of this study, several factors influencing Turkish farmers' willingness to use PPC and PPE are identified. For example, farmers preferred wearing regular clothes for comfort and they desired to appear aesthetically appealing. One participant indicated that he was given gloves, coveralls, and a mask; nonetheless, he chose to wear regular work clothes for comfort reasons. Consequently, we can hypothesize that the beliefs might influence behaviors; for instance, beliefs regarding farmers' insusceptibility to pesticides and 
developing immunity to cancer are not likely to be associated with appropriate use of protective clothing. Risky behavior was also demonstrated while performing pesticide activities including smoking in the fields, walking into public areas without showering, or failing to change contaminated work clothes. These unsafe practices might stem from farmers' lack of understanding of safe pesticide activities. Therefore, measuring farmers' existing knowledge about the use of pesticides helps pave the way for future respective educational programs.

Lastly, participants indicated that they did not receive training on the type of appropriate clothing to wear during pesticide activities. The authors suggest that the Turkish farmers would be more willing to use PPE and PPC, if they understand their importance in protection. In addition, if farmers were educated about surface contamination with contact, they might replace coveralls as PPC. The farmers suggested PPC resembled their regular work clothing, and that regular work clothing would be more acceptable than white coveralls already available in the market. Considering the hot and humid weather conditions in the Aegean region of Turkey, product developers and manufacturers need to come up with solutions that address the farmers' comfort needs. For example, similar to the cloth bandanas worn by Ecuadorian farmers (Grieshop, 1988), the Posu with modifications such as a protective finish, may provide more protection for farmers. With the provision of risk-taking behaviors of some farmers, governmental agencies, as well as the private sector, must address these issues through educational strategies.

Based on the farmers' responses, further modifications to interview schedule are recommended to distinguish the depth of farmers' knowledge. An expanded attitude scale could be utilized in future research to identify whether, and if so how, positive or negative attitudes toward pesticide usage are associated with other factors, such as their willingness to change clothing behaviors. Other societal attitudes also need to be investigated that may influence Turkish farmers' willingness to wear PPEs and PPCs. The participants were mostly small-scale landowners and might have had different needs than those of large landowners, as with many farmers in other regions of Turkey.

\section{References}

Bakirci, G. T., Acay, D. B. Y., Bakirci, F., \& Otles, S. (2014). Pesticide residues in fruits and vegetables from the Aegean region, Turkey. Food Chemistry, 160, 379-392. https://doi.org/10.1016/j.foodchem.2014.02.051

Damalas, C. A., Georgiou, E. B., \& Theodorou, M. G. (2006). Pesticide use and safety practices among Greek tobacco farmers: A survey. International Journal of Environmental Health Research, 16, 339-348. https://doi.org/10.1080/09603120600869190

DeJonge, J. O., Vredevoogd, J., \& Henry, M. S. (1983). Attitudes, practices, and preferences of pesticide users toward protective apparel. Clothing and Textile Research Journal, 2(1), 9-14. https://doi.org/10.1177/0887302X8300200102

Delen, N., Durmusoglu, E., Guncan, A., Gungor, N., Turgut, C., \& Burcak, A. (2005). Problems with pesticide use in Turkey, diminishing retention and sensitivity to organisms. 
[Turkiye'de pestisit kullanimi, kalinti ve organizmalarda duyarlilik azalisi sorunlari.] Paper presented at the Turkey Agricultural Engineering 6th Technical Congress. Ankara, Turkey.

Devi, P. I. (2009). Health risk perceptions, awareness and handling behaviour of pesticides by farm workers. Agricultural Economics Research Review, 22(23), 263-268.

http://purl.umn.edu/57410

Grieshop, J. I. (1988). Protective clothing and equipment: Beliefs and behavior of pesticide users in Ecuador. Paper presented at the Performance of Protective Clothing: Second Symposium, ASTM STP 989, Philadelphia, PA.

https://compass.astm.org/DIGITAL_LIBRARY/STP/PAGES/STP26349S.htm

Ibitayo, O. O. (2006). Egyptian farmers' attitudes and behaviors regarding agricultural pesticides: implications for pesticide risk communication. Risk Analysis, 26(4), 989-995. https://doi.org/10.1111/j.1539-6924.2006.00794

Isin, S., \& Yildirim, I. (2007). Fruit-growers' perception on the harmful effects of pesticides and their reflection on practices: The case of Kemalpasa, Turkey. Crop Protection, 26, 917-922. https://doi.org/10.1016/j.cropro.2006.08.006

Jones, E., Mabota, A., \& Larson, D. W. (2009). Farmers' knowledge of health risks and protective gear associated with pesticide use on cotton in Mozambique. Journal of Developing Areas, 42. 267-282. https://doi.org/10.1353/jda.0.002

Kachaiyaphum, P., Howteerakul, N., Sujirarat, D., Siri, S., \& Suwannapong, N. (2010). Serum cholinesterase levels of Thai chilli-farm workers exposed to chemical pesticides: Prevalence estimates and associated factors. Journal of Occupational Health, 52(1), 89-98. https://doi.org/10.1539/joh.Q9003

Lorenz, A. N., Prapamontol, T., Narksen, W., Srinual, N., Barr, D. B., \& Riederer, A. M. (2012). Pilot study of pesticide knowledge, attitudes, and practices among pregnant women in Northern Thailand. International Journal of Environmental Research and Public Health, 9, 3365-3383. https://doi.org/10.3390/ijerph9093365

Lu, J. (2009). Comparison of pesticide exposure and physical examination, neurological assessment, and laboratory findings between full-time and part-time vegetable farmers in the Philippines. Environmental Health and Preventive Medicine, 14, 345-352.

https://doi.org/10.1007/s12199-009-0105-x

Ministery of Food Agriculture and Livestock General Directorate of Vegetative Production. [T.C. Gida Tarim ve Hayvancilik Bakanligi Bitkisel Uretim Genel Mudurlugu] (2016). BUGEM activities. Ankara, Turkey.

Ngowi, A. V., Maeda, D. N., \& Partanen, T. J. (2001). Knowledge, attitudes and practices (KAP) among agricultural extension workers concerning the reduction of the adverse impact of pesticides in agricultural areas in Tanzania. La Medicina del lavoro, 93, 338-346. Retrieved from PMID: 12212403

Nicol, A., \& Kennedy, S. (2008). Assessment of pesticide exposure control practices among 
men and women on fruit-growing farms in British Columbia. Journal of Occupational and Environmental Hygiene, 5(4), 217-226. https://doi.org/10.1080/15459620701839846

Ohayo-Mitoko, G. J. A., Heederik, D. J. J., Kromhout, H., Omondi, B. E. O., \& Boleij, J. S. M. (1997). Acetylcholinesterase inhibition as an indicator of organophosphate and carbamate poisoning in Kenyan agricultural workers. International journal of occupational and environmental health, 3(3), 210-220. https://doi.org/10.1179/oeh.1997.3.3.210

Perkins, H. M., Crown, E. M., Rigakis, K. B., \& Eggertson, B. S. (1992). Attitudes and behavioral intentions of agricultural workers toward disposable protective coveralls. Clothing and Textile Research Journal, 11(1), 67-73. https://doi.org/10.1177/0887302X9201100110

Rucker, M. H., McGee, K. M., \& Chordas, T. (1986). California pesticide applicators' attitudes and practices regarding the use and care of protective clothing. In R. L. Barker \& G. C. Coletta (Eds.), Performance of protective clothing : A symposium sponsored by ASTM Committee F-23 on Protective Clothing, Raleigh, NC, 16-20 July 1984. Philadelphia, PA: American Society for Testing and Materials [ASTM].

Salvatore, A. L., Bradman, A., Castorina, R., Camacho, J., López, J., Barr, D., \& Eskenazi, B. (2008). Occupational behaviors and farm workers' pesticide exposure: Findings from a study in Monterey County, California. American Journal of Industrial Medicine, 51, 782-794. https://doi.org/10.1002/ajim.20622

Singh, A., \& Kaur, M. (2012). A Health surveillance of pesticide sprayers in Talwandi Sabo Area of Punjab, North-West India. Journal of Human Ecology-New Delhi, 37(2), 133. http://indiaenvironmentportal.org.in/content/347455/a-health-surveillance-of-pesticide-spraye rs-in-talwandi-sabo-area-of-punjab-north-west-india/

Singh, B., \& Gupta, M. (2009). Pattern of use of personal protective equipments and measures during application of pesticides by agricultural workers in a rural area of Ahmednagar district, India. Indian Journal of Occupational \& Environmental Medicine, 13, 127-130. https://doi.org/10.4103/0019-5278.58915

Stone, J., Padgitt, S., Wintersteen, W., Shelly, M., \& Chisholm, S. (1994). Iowa greenhouse applicators' perceptions and use of personal protective equipment. Journal of Environmental Health, 57, 16-22.

http://lib.dr.iastate.edu/cgi/viewcontent.cgi?article=1004\&context=pols_pubs

The Union of Chambers and Commodity Exchanges of Turkey [ Turkiye Odalar ve Borasalar Birligi]. (2013). Turkiye Tarim Sektoru Raporu, (Report \# 2014/230). In T. yayini (Ed.). Ankara, Turkey.

Yassin, M., Mourad, T., \& Safi, J. (2002). Knowledge, attitude, practice, and toxicity symptoms associated with pesticide use among farm workers in the Gaza Strip. Occupational and Environmental Medicine, 59, 387-394. https://doi.org/10.1136/oem.59.9.650

Zeren, O., Dikmen, N., \& Taga, S. (2002). Measuring the exposure to organophosphorous insecticides of people involved in crop protection in Turkey. Agriculture, Ecosystems \& 


\section{Macrothink}

Environment, 93(1), 447-448. https://doi.org/10.1016/S0167-8809(02)00041-5

Zyoud, S., Sawalha, A., Sweileh, W., Awang, R., Al-Khalil, S., Al-Jabi, S., \& Bsharat, N. (2010). Knowledge and practices of pesticide use among farm workers in the West Bank, Palestine: Safety implications. Environmental Health Prespective Medicine, 15, 252-261. https://doi.org/10.1007/s12199-010-0136-3

\section{Copyright Disclaimer}

Copyright for this article is retained by the author(s), with first publication rights granted to the journal.

This is an open-access article distributed under the terms and conditions of the Creative Commons Attribution license (http://creativecommons.org/licenses/by/3.0/). 